\title{
Концептуальная конгруэнтность фотоприемников на основе многослойных структур с квантовыми ямами и сверхрешеток
}

\author{
Козлов А.И.
}

ИФП СО РАН, 630090, Россия, Новосибирск, пр. Ак. Лаврентьева, 13

DOI 10.34077/Semicond2019-445

Аналитические значения эквивалентной шуму разности температур (NETD) инфракрасного фотоприемника (ИК ФП) оценивается как отношение напряжения шума системы, включающей ИК фоточувствительный элемент (ФЧЭ) и канал считывания мультиплексора, к температурной чувствительности ИК ФЧЭ при данной квантовой эффективности ๆ:

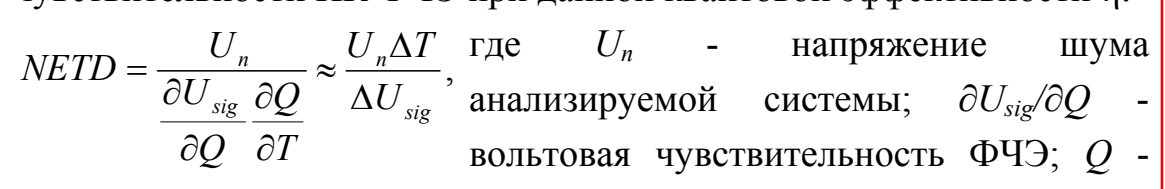
входной поток фотонов; $\partial Q / \partial T$ - температурный градиент; $\Delta T$ разность температур на входе оптической системы; and $\Delta U_{\text {sig }}$ разность сигнального напряжения для данной разности $\Delta T$ [1-4].

Полученные значения NETD для многослойных структур с квантовыми ямами (МСКЯ) на GaAs/AlGaAs (1-4) и сверхрешеток (CР) на InAs/GaInSb (5,6) иллюстрируют Puc.1-Puc.4 [3, 4, 5]. ИК ФП на основе МСКЯ с длиной волны максимума спектральной чувствительности $\lambda_{\max } \approx 9 \mu \mathrm{m}$ начинает обеспечивать близкое к режиму ограничения фоном, практически предельное разрешение по температуре, лучшее, чем ИК ФП на СР при параметре $\mathrm{R}_{0} \mathrm{~A}$ более 500 Ом см $^{2}$ и $\eta \geq 0.1$ (Puc. 1) $[3,4,5]$. С уменьшением $R_{0} A$ параметра МСКЯ и СР фотодетекторов NETD ИК ФП ухудшается. По мере уменьшения линейного размера ФЧЭ $\left(l_{\text {Фэ })} N E T D\right.$ ФП на основе МСКЯ монотонно увеличивается; но при $\eta \geq 0.1$ СР ФП проигрывают МСКЯ ФП в отношении NETD (Puc. 2) [3,4]. При $\eta \approx 0.05$ не требуется зарядовой емкости интегратора мультиплексора $Q_{R O I C}$ более 8 пКл, а при $\eta$ порядка 0.1 требуется $Q_{R O I C}$ не более 14 пКл (Pис. 3) [4]. $Q_{R O I C}=C_{\text {int }} E_{P}$, где $C_{\text {int }}$ - емкость накопления; $E_{P}$ - рабочее напряжение технологии мультиплексоров. МСКЯ ФП обеспечивает лучшие значения NETD в сравнении с CP ФП практически во всем диапазоне $Q_{R O I C}$ при $\eta \geq 0.1$ (cM. Puc. 3) [4]. В диапазоне $\lambda_{\max } \approx 8.5-9.5 \mu \mathrm{m}$ МСКЯ ФП предоставляет хорошее (67) $\mathrm{mK}$ температурное разрешение, практически независимо от $\eta$, $N E T D$ определяется шумом фонового излучения [4]. NETD МСКЯ ФП при $\eta=0.05 \div 0.2$ в диапазоне $\lambda_{\max }<10 \div 11 \mu$ м меньше, чем NETD CР ФП. При дальнейшем увеличении $\lambda_{\max }$ наблюдается рост NETD с существенным преимуществом для больших значений $\eta$ фотодетекторов (Pис. 4) [3, 4].

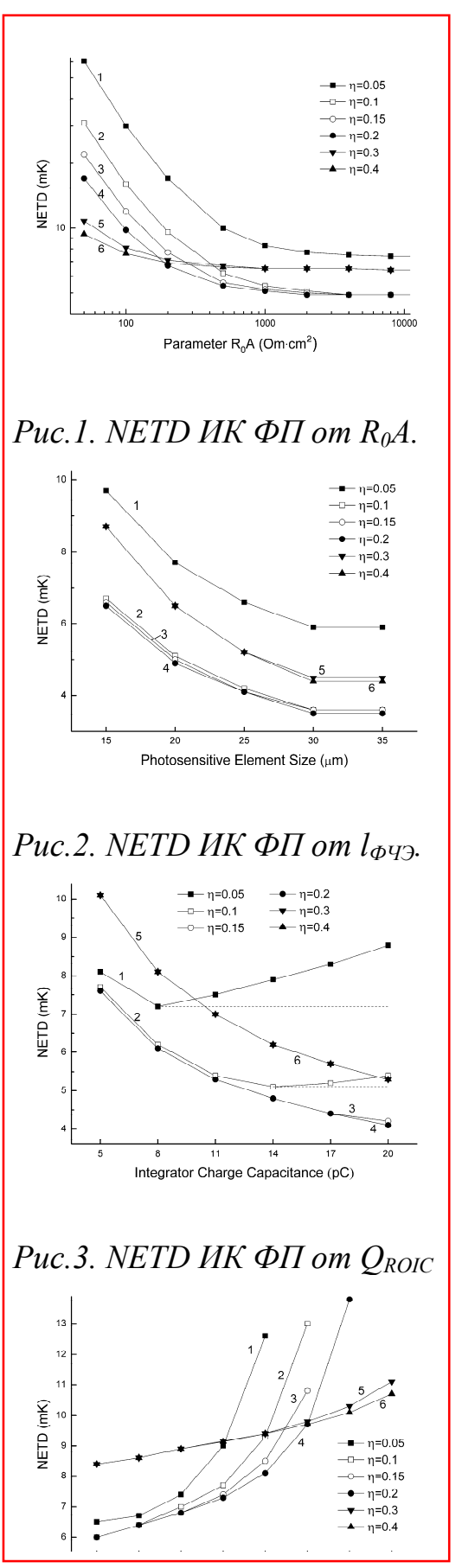

[1] А.И.Козлов, Оптический журнал, 77, 7, 421-428 (2010).

[2] А.И.Козлов, В.В.Васильев, И.В.Марчишин, et al., Оптический журнал, 81, 7, 39-45 (2014).

[3] А.И.Козлов, М.А.Демьяненко, В.Н.Овсюк, Оптический журнал, 83, 9, 64-71 (2016).

[4] А.И.Козлов, М.А.Демьяненко, В.Н.Овсюк, Оптический журнал, 84, 9, 59-65 (2017).

[5] A. Rogalski, Progress in Quantum Electronics, 36, 342-473 (2012). 